\title{
X ve Gama-Işını Dedektörlerinde Ölü Zaman Düzeltmesi İçin Bir Program
}

\author{
Salih Mustafa KARABIDAK ${ }^{1 *}$, Özkan BINGÖL ${ }^{2}$, Ali KAYA ${ }^{1}$, Selim KAYA $^{1}$ \\ ${ }^{1}$ Gümüşhane Üniversitesi, Mühendislik ve Doğa Bilimleri Fakültesi, Fizik Mühendisliği Bölümü, TR-29100, \\ Gümüşhane, Türkiye \\ ${ }^{2}$ Gümüşhane Üniversitesi, Mühendislik ve Doğa Bilimleri Fakültesi, Yazılım Mühendisliği Bölümü, TR-29100, \\ Gümüşhane, Türkiye
}

Geliş tarihi/Received 13.11.2015

Düzeltilerek geliş tarihi/Received in revised form 11.01.2016

Kabul tarihi/Accepted 15.01.2016

\begin{abstract}
$\ddot{O}$ zet
X ya da gama ışını detektörlerinin kullanıldı̆̆ spektrometrik kantitatif ve kalitatif analizlerinde, analizlerin doğruluğu için sayma kayıplarının belirlenmesi ve telafi edilmesi önemlidir. Spektrometrelerdeki bu sayma kayıpları uzatılan ve uzatılmayan sistem ölü zamanlarından meydana gelir. Bu çalışmada, bu kayıpları telafi etmek için bir bilgisayar program geliştirilmiştir. Programı test etmek için deneysel çalışmalar yapılmıştır. Program, DELPHI program derleyicisiyle kodlanmıştır. Program, ölü zaman düzeltme, özgün pik arama, özgün grafik modülü, yazılım arayüzü ve program sonucunu rapor halinde veren rapor modüllerden oluşmaktadır. Bu programda düzeltme yapılmamış veya düzeltme yapılmış spektrumları ayrı ayrı irdeleme imkânı să̆lanmıştır.
\end{abstract}

Anahtar Kelimeler: X Işsıları, Gama Işınları, X-Gama Detektörleri, Sayma Kaybı, Ölü Zaman, Bilgisayar Programı.

\section{A Program for Dead Time Correction at X and Gamma-Rays Detectors}

\begin{abstract}
Determination of compensating for count losses for the correctness of analyses in spectrometric analysis of qualitative and quantitative use of $x$-gamma ray detectors are of importance. These counting losses in spectrometry are due to paralyzable and non-paralyzable system dead time. In this work, a computer program was developed for compensate to counts losses due to dead time. Experimental studies were performed to test of this program. This program was coded by DELPHI program compiler. The program consists of original dead time correction, peak search, graphics module, program interface, a report module. In this program, either corrected or uncorrected spectra is given the opportunity to examine separately.
\end{abstract}

Keywords: X Rays, Gamma Rays, X-Gamma Rays Detectors, Counting Loss, Dead Time, Computer Programs.

\footnotetext{
*Salih Mustafa KARABIDAK, smkarabidak@gumushane.edu.tr, Tel: (456) 2337425 


\section{Giriş}

Günümüzde "radyasyon" kelimesini duymayan hemen hemen yok gibidir. Radyasyon kelime olarak 1şık veya isı yayan demektir. Her ne kadar alfa ve beta parçacıkları 1şık ve 1sı saçan değilse de radyasyon olarak ifade edilmiştir. Radyasyon; normalde bulundurulması gerekenden fazla enerjiye sahip olan molekül, atom ve atom çekirdeği tarafından yayımlanan yüklü ve yüksüz parçacıklar ile elektromanyetik dalga olan enerji paketlerine (fotonlara) verilen addır. Alfa parçacıkları, beta parçacıkları ve gamma 1şını gibi elektromanyetik dalga fotonları doğal olarak oluşan farklı radyasyon tipleridir. Canlıların ihtiyacı olan ve kullanım alanlarını saymakla bitiremediğimiz enerji, güneşten elektromanyetik radyasyon yoluyla bize ulaşmaktadır. Her tip radyasyon kendine has enerji taşır ve az veya çok üzerine düştüğü maddeye tesir ederek değişik reaksiyonlara yol açar.

Elektronlar ve protonlar arasındaki etkileşmeleri ve çok yüksek enerjiye sahip olan kararsız atomların bazı parçacıklar yayarak kararlı hale gelmeleri olayları elektromanyetik dalga ya da radyasyon olarak ifade edilir. $\mathrm{Bu}$ nedenle elektromanyetik radyasyon genel olarak ikiye ayrilır: Ultraviyole, görünür 1ş1k, kızıl ötesi, mikrodalgalar, radyo ve TV dalgaları ve güç aktarımı şekillerinde ifade edilen iyon oluşturmayan (iyonize olmayan) radyasyon ve x-1şını, alfa, beta, gama ve kozmik 1şınları gibi madde ile etkileşme yaptığında iyon oluşturan (iyonize) radyasyondur. Elektromanyetik dalgalar ya da radyasyon, düşük enerjili radyo dalgalarından yüksek enerjili gama 1şınlarına uzanan yelpazede yayılan enerji dalgalarıdır. Gama ve x ışını spektrumu elektromanyetik radyasyonun küçük bir kısmını oluşturur. Elektromanyetik dalgalar bir genliğe ve dalga pikleri arasında uzunluğa (dalga boyuna) sahiptir.

Elektromanyetik radyasyonun genel bir özelliği, elektrik ve manyetik alanda depolanan enerjinin dalga paketçikleri biçiminde uzayda taşınmasıdır. Herhangi bir elektromanyetik radyasyon $\lambda$ dalga boyu, $v$ frekansı veya bunlara eşdeğer E enerjisi ile tanımlanabilir. Boşlukta bu nicelikler birbirleriyle ilişkilidir. Burada c elektromanyetik radyasyonun hizı ve h Planck sabitidir. Genel olarak; radyo dalgaları frekans biriminde (genellikle $\mathrm{MHz}$ ), orta ölçekli radyasyonlar dalga boyu biriminde (genellikle $\mathrm{cm}$ ), gama ve $\mathrm{x}$ 1şınları enerji biriminde ifade edilir (genellikle $\mathrm{keV}$ ). Radyasyon miktarı toplam enerjiyle veya bireysel enerji paketçikleri (foton) ile tanımlanabilir (Debertin ve Helmer,1988).

İyi tanımlanmış bir kaynak tarafından yayımlanan radyasyonun şiddeti dalga boyu, frekans ya da enerjinin bir fonksiyonu olarak çizilirse, elektromanyetik radyasyon spektrumu genel olarak dört tipik şekilde ortaya çıkar: a) sürekli spektrum, b) çizgi spektrumu, c) çizgi ve sürekli spektrumun bir bileşimi ve d) detektör çözünürlüğüne bağlı olarak çizgi spektrumunun genişlemiş hali. Bir spektrumun her bir çizgisi veya farklılığ kuantum teorisi tarafından tanımlanan 1şın yayan sistemlerin farkli enerji seviyeleri arasındaki bir geçişten ileri gelir. Sistem eşsiz bir enerji değerine sahip bir durumda bulunurken bozunarak yine eşsiz ve daha düşük enerjili bir duruma geçer.

Spektrumdaki bir bileşenin şiddeti veya büyüklügü her bir ayrı pikin veya sürekli dağılımın altındaki alandır. Birçok durumda, kendi kendine ölçülen bu alan ilgilenen alanın miktarını vermez. Örneğin, farklı enerjilerde farklı sayma verimlerine sahip foton belirleme sistemlerinin kullanılması spektrumu bozar. $\mathrm{Bu}$ nedenle doğrudan gözlenen pik alanları bazı araç ve yöntemlerle sürekli olarak düzeltilmelidir. Spektrum, detektör üzerine düşen farklı enerjili fotonların oluşturduğu ve bir takım elektronik aygitlar kullanılarak elde edilen şekillenişlerdir. Matematiksel olarak düzeltme, gözlenen spektrumun ölçümde kullanılan detektörün cevap fonksiyonu ile girilen spektruma katlanmasıdır (üzerine ilave edilmesidir: convolution). Detektörler, genellikle spektrum çizgilerini ve sürekli bileşenlerin bir bileşimini bir çizgi spektrumuna çevirir. $\mathrm{Bu}$ nedenle deneysel 
çalışanlar, kaynak tarafından yayımlanarak oluşturulan spektrumun karakteristikleri ile ilgili çıkarılacak bilgiler için gözlenen karmaşı spektrumu doğru olarak yorumlamalıdırlar (Debertin ve Helmer, 1988).

X-1şınlarını, Röntgen 8 Kasım 1895'te keşfedilmiştir. Röntgen bu 1şınların ne olduğunu anlayamadığ 1 için bilinmeyen manasında " $X$ " olarak adlandırmıştır. Bir elektron demetinin çok hılı yavaşlatılması ile üretilen ve gama radyasyonuna benzer yüksek enerjili fotonlardır. Bunlar da gama 1şınları gibi yüksek enerjili girici 1şınlar olup, gamalardan tek farkları atom çekirdeklerinden değil, atomların iç elektron kılıfindan salınmalarıdır. Gama 1şınları atomun çekirdeğinde oluşur. Atom çekirdeğinin bozunumu sırasında çekirdekten salınan elektromanyetik dalgalardır. Gama 1şıması sürdüren bir çekirdekte atom kütle numarası ve atom numarası değişikliğe uğramaz. Işık hızıyla hareket eden gama 1şınlarının enerjileri çok yüksek olduğundan madde ile etkileşime girene kadar epeyce yol alır.

Elektromanyetik radyasyonun her bir enerji bölgesi için spektrometre gelişimi deneysel araçların gelişimine paralel olarak ilerlemiştir. İlk ve kaba detektörler genellikle radyasyonunun varlığını belirlemede kullanılmıştır. İkinci nesil detektörler ise radyasyonun enerji bilgisinin çok az bir kısmını vermekle birlikte radyasyon şiddetini belirlemede kullanılmıştır. Son tür detektörler ise radyasyon varlığını ve şiddetini belirleme yanında şiddeti foton enerjisinin bir fonksiyonu olarak verme noktasına gelmiştir.

Sayma, sayma oranı ve pile up kayıplarının ana nedeni ölü zamandir. Bunlarla ilgili gerekli düzeltmeleri yerine getirebilmek için öncelikle ölü zaman belirlenmelidir. Bazen ölü zaman sayma sisteminin elektronik devresinin sabit ayırma zamanı gibi bilinen sınırlı özellikleri ile de ilişkilidir. Ölü zamanın işlem şartları ile bilinemeyeceği veya değişebileceğinden dolayı doğrudan ölçülmesi genel kabul görmüştür. Ölü zamanın genel ölçme teknikleri doğru sayma oranı ile lineer olmayan bir biçimde değişen gözlenen sayma oranı gerçeğine dayalıdır. Bu nedenle belirli modellerden birinin uygulanabilir olduğu varsayımıyla ve en azından iki farklı doğru sayma oranları için gözlenen sayma oranlarının ölçülmesiyle ölü zaman ölçülebilir (Knoll, 2000). Bu çalışmada ölü zamanın analitik olarak belirlenebilmesi için yükseltici ve ADC'yi kapsayan bir ölü zaman denklemi türetilmiştir.

\section{1. Ölü Zaman Düzeltmesi İçin Bazı Modeller}

Ayrıca ölü zaman pile up kayıpları üzerinde de etkilidir. Çünkü ölü zamanı azaltmak için yapılan iyileştirmeler beraberinde pile up kayıplarına neden olabilmektedir. Bu nedenle sayma sisteminde kullanılan elektronik aygıtlar en iyi sonuçları verecek şekilde ayarlanmalı ve kurgulanmalıdır. Detektörün gerçek cevabını belirlemek için ölü zaman nedeniyle kaybolan bu pulslar belirlenmeli veya ölçülmelidir. Bunun için genel olarak yüksek ya da düşük sayma oranlarında gelen pulsların olduğu durum normal durum olarak kabul edilir ve bu durumda kesirsel kayiplar değişmez (Gilmore ve Hemingway, 2003). Sayma sistemimin ölü zamanından kaynaklanan sayma kayılarını telafi etmek için literatürde birkaç yöntem vardır. Bunlar aşağıda ifade edilmiştir.

\subsection{1. İşlem Zamanı Saati Yöntemi}

Çok kanallı analizör (MCA) ölü zaman kayıpları giriş kapısı boyunca belirli olduğu varsayıldığında ölçümün uygun sayma süresi gerek ve yeter şart olduğu için toplam işlem zamanı dikkate alınır. Yani işlem zamanı, sistem açık ve toplanan sayma için mevcutsa gerçek zamandır. Böylece spektral piki içindeki saymalar saniye başına saymayı belirlemek için işlem zamanına bölünebilir. $\mathrm{Bu}$ yöntem düşük sayma durumlarında iyi (Gilmore ve Hemingway, 2003) olsa da uzun sayma süreleri gerektirir ve gerçek sayma oranını belirlemede yetersizdir.

\subsubsection{Gedcke-Hale Yöntemi}

$\mathrm{Bu}$ yöntem $\mathrm{EG \& G}$ Ortec firması tarafindan kullanılır ve istatistiksel düzeltmeyi içerir. $\mathrm{Bu}$ 
yöntem de yükselticinin önde gelen pile up kenarından kaynaklanan kayıpları telafi edilir. $\mathrm{Bu}$ yöntem kabaca (Gilmore ve Hemingway, 2003)

Hafızadaki Sayma = Gelen Sayma $\times \frac{T_{\text {isslem }}}{T_{\text {Gerçek }}}$

şekliyle ifade edilebilir. Çok yüksek sayma oranlarında kullanılır. Fakat maksimum çıktıda yaşanan zaman sabiti doğruluğuna \% \pm 3 civarında katkı yapmaktadır.

\subsubsection{Puls Üreticisinin Kullanımı}

Detektörden çıkan pulslara benzer sabitlenmiş bir genlikte puls üreticisinde yapay olarak üretilen pulslar bilinen oranda ön yükselticiye gönderilir. Üretilen bu pulslar tüm sayma sistemi bileşenleri boyunca taşınır ve bir pulser pikinde hafizada toplanır. Bu durumda pulser sayması ile sürdürülen kesirsel kayıpların gama 1şınları ile üretilen kesirsel kayıplarla aynı olduğu varsayılır. Böylece gama spektrumunda ölü zaman kayıpları (Gilmore ve Hemingway, 2003).

Pulser Tarafından Üretilen Puls Sayısı

Pulser Pikinde Kaydedilen Pulser Sayması

temel oranı ile ifade edilen gama pik alanı ile çarpılması ile belirlenir. Wilkinson türü ADC'lerde ölü zaman puls yüksekliğinin bir fonksiyonudur. Sabit genlikle pulserde üretilen pulslar gerçek bir ölü zaman ifadesi vermesi bu nedenle problemlidir.

\subsubsection{Kayıp Serbest Saymast}

$\mathrm{Bu}$ yöntem birkaç farklı düzeltme içerir. $\mathrm{Bu}$ düzeltmelerin tümü anlık sayma oranını göstermek için bir alt devrenin kullanılmasına ve bir $\mathrm{n}$ ağırlık çarpanının üretilmesine dayanır. $\mathrm{n}$ bir tamsayıdır ve gerçekleşen sayma sonucu oluşan bir puls yerine $\mathrm{n}$ tane puls eklenir. Böylece anlık yüksek sayma oranı zamanında uygun olan spektrumdaki bir kanala yüksek bir sayma yansitılır. Bu yöntem içinde yer alan Harms usulünde işlem için mevcut olan pulslar sayılır fakat sistem meşgul olduğu zaman bu pulslar reddedilir.
Böylesi bir sayıcıda reddedilen pulsların sayısı belirlenir ve bir sonraki gerçek olayda bu ağırlık kullanılır. Yüksek sayma oranlarında daha etkin hale gelen pile up kayıpları bu usulde dikkate alınmadığından sorunludur. Gerçek puls üreticisi usulü Westphal tarafindan geliştirildi. Kabaca puls üreticisi yöntemine benzer ve bunun yanında Harms usulünde yer almayan yükselticinin pile up pulslarını dikkate almıştır (Gilmore ve Hemingway, 2003).

Serbest kayı saymasının sorunlarından biri genel ölçüm istatistiğinin geçersiz olmasıdır. Yani Poisson istatistiği bu yöntemde geçersizdir.

\subsubsection{Sıfır Ölü Zaman Sayması}

Gama 1şını spektrometresinde değişen ölü zaman problemi hatanın iyi bilinen bir kaynağıdır. Böylesi şartlar altında ölü zaman düzeltmeleri, değişen ölü zaman ölçülen radyoizotopu baskın bir şekilde etkilerse doğru olabilir (Blaauw vd., 2001; Blaauw ve Fleming, 2003). Sifır ölü zaman düzeltmesi kayı serbest sayması ile hemen hemen aynıdır. Yani kanal sayısına karşılık gelen olayın belirlenmesi anında spektrometre ölü zamanına bağlı olarak spektrumdaki bir kanala birden fazla ilave olayın eklenmesine dayanır. Aralarındaki fark, Gedcke-Hale (Jenkis vd., 1981) işlem zamanına dayalı anlık ölü zamanın belirlenmesindeki yönteme bağlı olması ile birlikte sıfır ölü zaman saymasında sıfır ölü zaman düzeltmelerinin tamamen sayılaștırılmasıdır. Bu nedenle bu model kullanılarak yapılan düzeltilmiş spektrum Poisson istatistiğini sağlamaz. Bu da sayma düzeltmelerinde bir problem teşkil eder.

\section{Metaryal ve Yöntem}

\subsection{Deneysel Çalışmalar}

Deneysel çalışmalar gama 1şınları ve $\mathrm{NaI}(\mathrm{Tl})$ sintilasyon detektörü ile yapılmıştır. $\mathrm{NaI}(\mathrm{Tl})$ sintilasyon detektörünün şematik görünümü Şekil 1'de gösterilmiştir. 


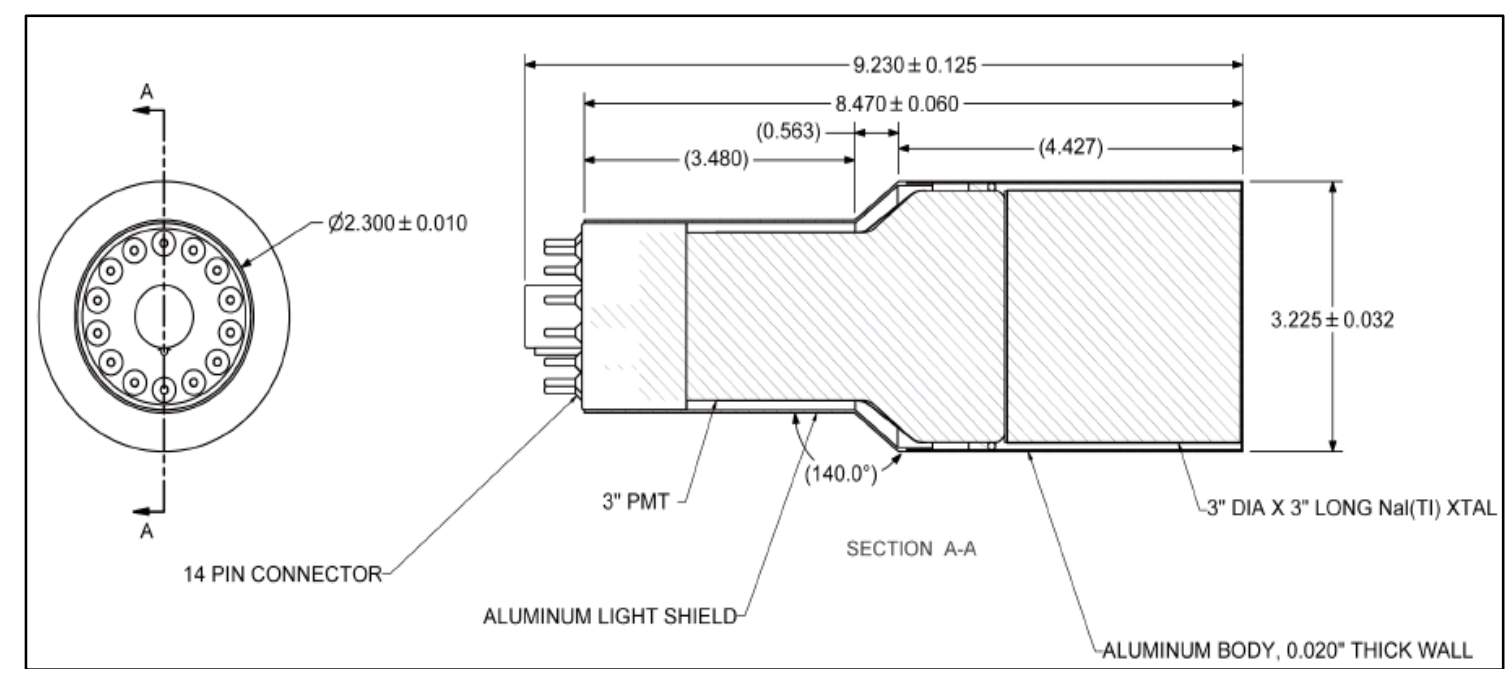

Şekil 1. NaI(Tl) sintilasyon dedektörü.

Sintilasyon detektörleri iki ana kısımdan oluşmakta olup çalışma şekli şematik olarak Şekil 2'de görülmektedir.

1) Üzerine yüklü bir parçacık (x-1şını, $\gamma$ 1 1şın1,...) düştüğü zaman 1 ş1k pırıltıları meydana getiren, küçük miktarlarda thallium veya europium gibi saf elementlerin sürüklendiği sodyum iyodür, sezyum iyodür, antrasin, naftalin ve fenantrin gibi maddelerden oluşan kristal kısım.

2) Oluşan 1şık pırıltılarını ölçülebilir bir voltaj pulsuna dönüştüren foto çoğaltıcı tüp kısmı.

Kristal üzerine düşen $\mathrm{x}$-1şınlarının soğurulması sonucu kristalde 1şı pırıltıları oluşur. $\mathrm{Bu}$ pırılttlar foto çoğaltıcı tüpe geçerek foto katot yüzeyden elektronların sökülmesine neden olur. Sökülen bu elektronlar, 800 ile 1500 voltluk potansiyel uygulanan peş peșe ve voltaj artmaları olacak şekilde yerleştirilen birçok metal çoğaltıcıya doğru sürüklenir. Sürüklenen bu elektronlardan çoğaltıcıya çarpan her elektron iki elektrona dönüşerek, tüp sonundaki çoğaltıcıda büyük miktarlarda elektron oluşmasını sağlar. Bu olayın tamamı bir mikro saniyeden daha kısa sürelerde gerçekleşir. $\mathrm{Bu}$ elektronlar burada bir yük pulsuna dönüştürülür. $\mathrm{Bu}$ pulsun yüksekliği gelen fotonların enerjisiyle orantılıdır. $\mathrm{Bu}$ pulslar yükseltilerek bir sayıcı ile sayılır. (Damla, 2009).

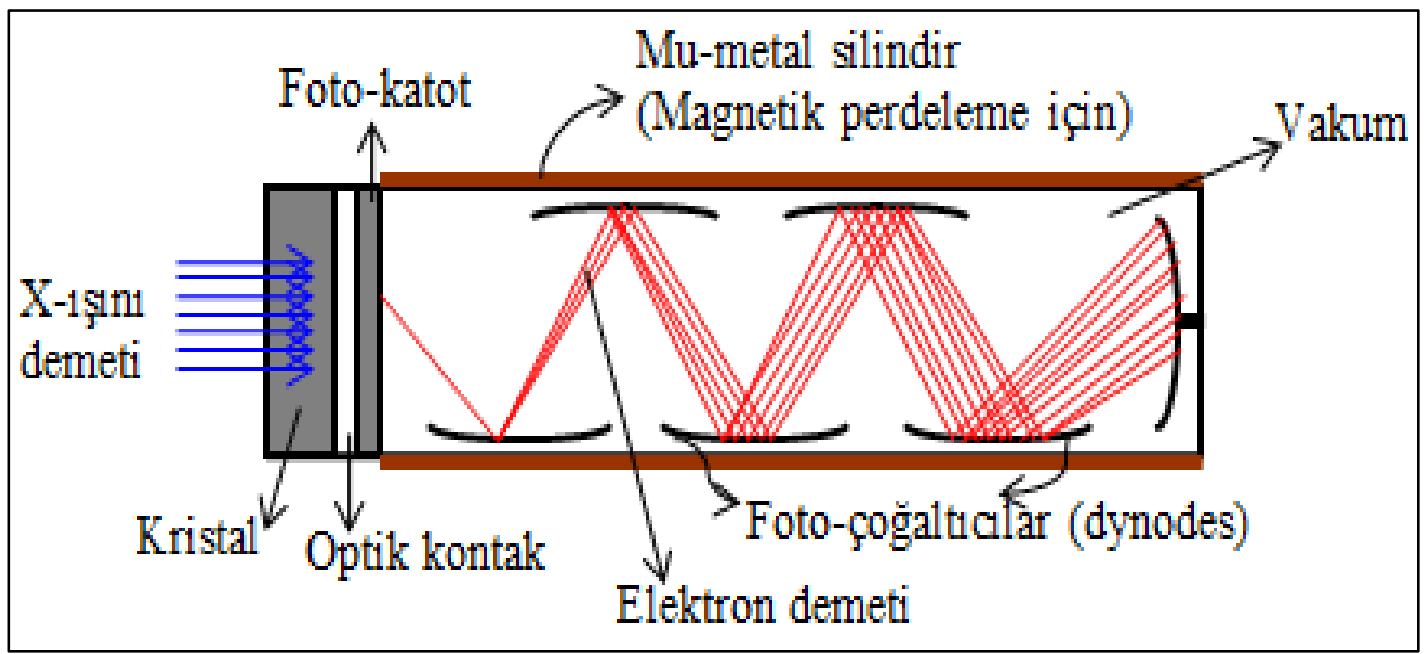

Şekil 2. Sintilasyon dedektörlerin şematik gösterimi. 
Gama ışını çalışmaları katkılandırılmış bazı beton blokların soğurma katsayılarının belirlenmesi üzerine yapılmıştır. Bu deneysel çalışmalar için hazırlanan deney düzeneği
Şekil 3'te görülmektedir. Numuneler 662 keV'lik gama enerjisine sahip Cs-137 gama kaynağına maruz bırakılmıştır (Ertaş, 2014).

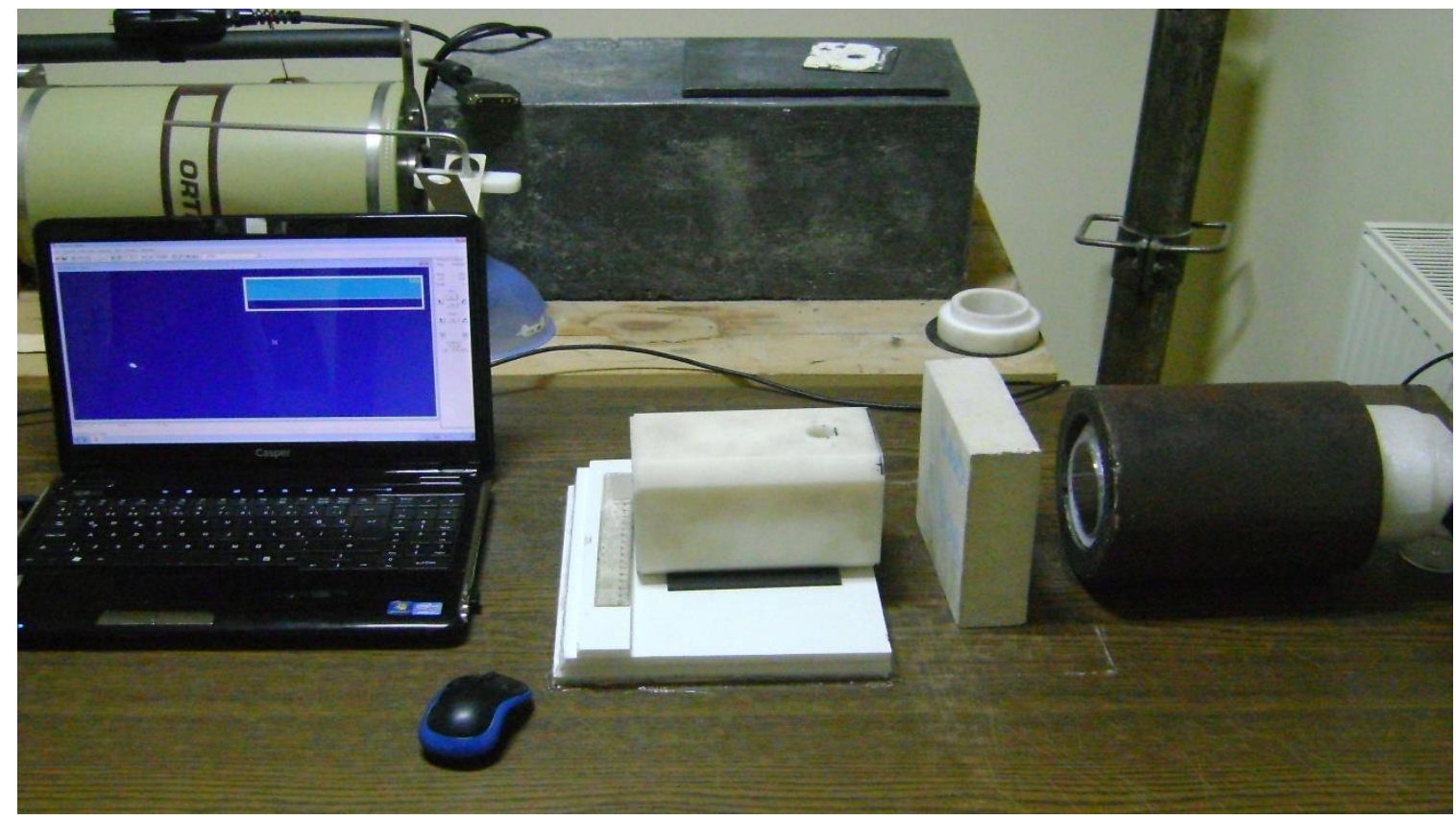

Şekil 3. Radyasyon zırhlama deney düzeneği.

Fotopik alanları, bu proje kapsamında kodlanan ve geliştirilen özgün pik aramayı içeren BACKGROUND, SMOOTH ve RAPOR programları kullanılarak tabii fon dikkate alınarak belirlendi.

\subsection{Teorik Çalışmalar}

Ölü zaman düzeltmesinde Karabıdak (2013) tarafından önerilen yöntem kullanılmıştır.

\subsubsection{Pik Bölgesinde Oluşan Sayma Hatasinın Belirlenmesi}

Tabii fona başlica katkı yapan iki durum numunenin bulunduğu ortamdaki çevresel arka plân ve analiz edilen bölgeden daha yüksek enerjiye sahip piklerinden gelen Compton arka plânıdır. Üçüncü bir arka plân katkıs1 analiz edilen fotopikten gelen katk1 olarak düşünülmelidir. Detektör içinde birçok etkileşmeye maruz kalan gama 1şınlarını varsaydığımızda üçüncü bir katkı yoktur. $\mathrm{Bu}$ ya spektral fotopike katk1 yapan fotoelektrik etkileşmelerin olduğu ya da fotopikin altında önemli olan maksimum enerjiye sahip Compton etkileşmelerinin olduğu etkileşmeler içindir. Diğer taraftan, gama 1şınları birden daha çok etkileşmeye maruz kalırsa bu durumda çoklu Compton olayları fotopikin hemen altındaki kanallara katkıda bulunabilir. Genel olarak yüksek ölçekte pik/tabii fon oranlı fotopikler için görünür olduğundan bu çoklu Compton olayları pikin sol tarafındaki tabii fonundan önemli ölçüde daha düşük olan sağ taraftaki tabii fona sahip piklere yol açar. Bu durum herhangi bir yerel tabii fon eğimine yol açar (Genie, 2000).

Herhangi bir kanalda "adım tabii fon"'uda denilen bu tabii fonu hesaplamak için pik bölgesinde aşağıdaki analitik fonksiyon kullanılır (Genie, 2000):

$B_{i}=L_{\text {ort }}+\frac{\sum_{j=L}^{i} Y_{j}}{\sum_{j=L}^{R} Y_{j}} *\left(R_{o r t}+L_{o r t}\right)$ 
Burada

$$
\begin{aligned}
L_{\text {ort }}= & \frac{\sum_{i=L-N+1}^{L} Y_{i}}{N} \\
R_{\text {ort }}= & \frac{\sum_{i=R}^{R+N-1} Y_{i}}{N}
\end{aligned}
$$

Burada i hesaplanacak tabii fonun bulunduğu kanal, L pik bölgesinin sol sınırını tanımlayan kanal, R pik bölgesinin sağ sınırını tanımlayan kanal, $\mathrm{N}$ ortalama tabii fonu hesaplamada kullanılacak kanalların sayısı, $\mathrm{L}_{\text {ort }}$ pikin sol tarafındaki ortalama tabii fon, $\mathrm{R}_{\text {ort }}$ pikin sağ tarafındaki ortalama tabii fondur. $Y_{j}, j$ kanalındaki toplam sayma ve $B_{i}$, i kanalı için hesaplanan tabii fondur. $\mathrm{N}$ değeri öngörülen FWHM'nin yarısına eşittir. Toplam $\mathrm{B}$ tabii fonu ilgilenilen tüm pik bölgesi üzerinden $\mathrm{B}_{\mathrm{i}}{ }^{\prime}$ lerin toplamıdır:

$$
B=\sum_{i=L}^{R} B_{i}
$$

Pik bölgesindeki $G$ toplam sayma, ilgilenilen tüm pik bölgesi üzerinden her bir kanaldaki saymaların toplamıdır ve

$$
G=\sum_{i=L}^{R} Y_{i}
$$

ile verilir. Böylece her bir kanaldaki net sayma

$$
P_{i}=Y_{i}-B_{i}
$$

ile verilir. $\mathrm{Bu}$ durumda net pik alan1 ilgilenilen tüm pik bölgesi üzerinden Pi'lerin toplamidir.

$$
P=\sum_{i=L}^{R} P_{i}=G-B
$$

Net pik alanındaki belirsizlik aşağıdaki ifadeyle verilir (Genie, 2000):

$$
\Delta P^{2}=G+\left[\frac{R-L+1}{2 N}\right] * B
$$

$\mathrm{Bu}$ belirsizliğe karşılık gelen yüzde hata aşağıdaki ifade ile verilir:

$\%$ hata $=\frac{\Delta P}{P} * 100$

Böylece toplam saymanın hesaplandığı pik bölgesindeki toplam net sayma hatas1

net hata $=\%$ hata $* P$

ifadesi ile verilir.

\subsection{Program Çalışmalart}

Bu çalışmada, DELPHI program derleyici ile BACKGROUND, SMOOTH, RAPOR, DUZSAY, GRAPH programları kodlanmış olmakla birlikte bu programların her birinin birlikte sunulduğu ÖZDU arayüz programı kodlanmıştır.

\subsubsection{BACKGROUND Programı}

Proje kapsamında geliştirilen bu program özgün pik arama modülüdür. Uygun uzantılı spektrum dosyası adı ve spektrumdaki kanal sayısı girilerek pik araştırması yapılacak spektrum dosyası açılır. Her bir kanaldaki sayma bir değişkene atanır. Her bir kanaldaki sayma değeri sayma(i) değerine atanır. Burada i kanal numarasını göstermektedir. Buna bağlı olarak ardışık iki kanal arasındaki fark

$$
\operatorname{delta}(i)=\operatorname{sayma}(i+1)-\operatorname{sayma}(i)
$$

ifadesi ile hesaplanır. Burada i kanal numarası olduğundan delta(i) ifadesi aynı zamanda ardışık iki kanal arasındaki eğimi ifade etmektedir. Bu işlemin hemen ardından

$$
\text { mutdelta }(i)=|\operatorname{delta}(i)|
$$

eğimin, mutlak eğimi elde edilir. Aynı zamanda

$$
\text { topdelta }=\sum_{i=k \text { analsaysst }-1} \operatorname{delta}(i)
$$

ifadesi kullanılarak tüm spektrum için toplam eğim değeri elde edilir. Bu topdelta değerine 
bağlı olarak spektrumun her bir kanalına bir filtreleme uygulanır:

$\operatorname{mutdelta}(i) \begin{cases}<\text { topdelta } & \text { imut }(i)=0 \\ \geq \text { topdelta } & \text { imut }(i)=1\end{cases}$
Buna bağlı olarak her bir kanal 0 ya da 1 değerine eşdeğer kılınarak spektrum bölgelere ayrılmıș olur. Bölgelerin sınır değerleri olarak 0 değeri kabul edilir. Spektrumun bölgelere ayrılması Şekil 4'te gösterilmiştir.

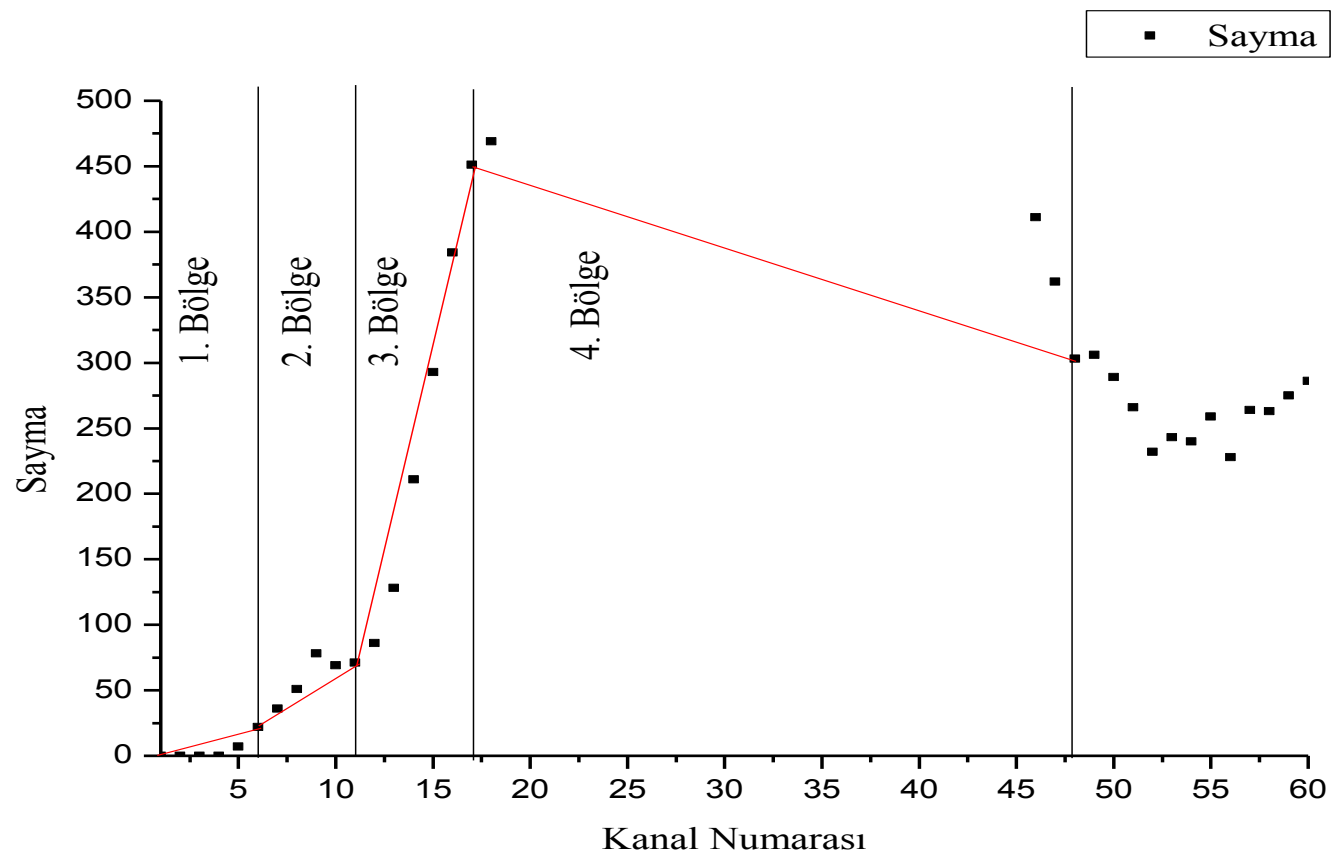

Şekil 4. BACKGROUND programında spektrumun bölgelere ayrılması.

Bölgelere ayrılan bu spektrum için bu bölgeler baz olmak üzere

$$
\operatorname{tabiifon}(i)=(i-i l k)\left(\frac{\operatorname{sayma}(\text { son })-\operatorname{sayma}(i l k)}{\text { son }-i l k}\right)
$$

ifadesi ile her bir kanala karşıllk gelen tabii fon sayması hesaplanır. Burada ilk ve son ifadeleri pik bölgesini sınırlayan sinır bölgesinin ilk ve son kanal numarasinı göstermektedir. Bu sonuç dikkate alınarak her bir kanal tabii fondan arındırılmış net sayma

$$
\text { netsayma }(i)=\operatorname{sayma}(i)-\operatorname{tabiifon}(i)
$$

denklemi ile elde edilir. Şayet sonuç negatif ise bu denklem sonucu sıfir kabul edilir. Şekil 5 'te tabii fonlu (backgroundlu) ve tabii fonsuz (backgroundsuz) pikler birlikte verilmiştir. Böylece elde edilen net sayma kullanıcı tarafindan adlandırılan yeni bir spektrum dosyasına yazdirılır.

\subsubsection{SMOOTH Programı}

BACKGROUND programın sonucu olarak yazdirılan uygun uzantılı spektrum dosyas1 adı ve spektrumdaki kanal sayısı girilerek düzleştirilmesi istenen spektrum dosyası açılır. Her bir kanaldaki sayma bir değișkene atanır. Her bir kanaldaki net sayma değeri netsayma(i) değerine atanır. Burada i kanal numarasını göstermektedir. Daha sonra aşağıda verilen bilgiler program boyunca irdelenir. Her bir kanaldaki sayma'daki $\sqrt{\text { sayma }}$ belirsizliği nedeniyle hem tabii fonda hem de karakteristik pikin eğiminde hayali maksimumlar oluşabilir. Burada i. kanaldaki sayma ifadesi $\mathrm{y}_{\mathrm{i}}$ ile göstereceğiz. 


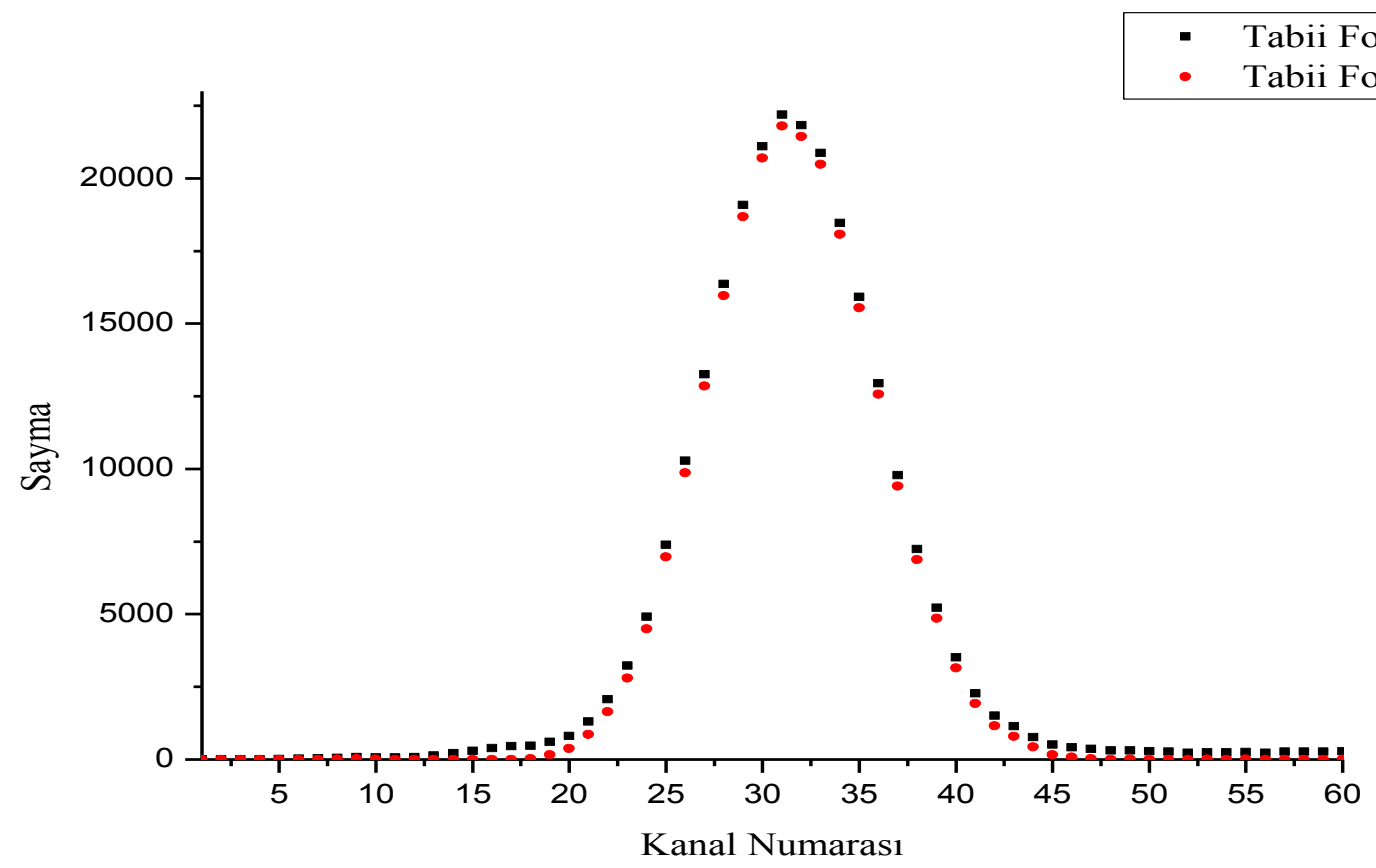

Şekil 5. BACKGROUND programı sonucu tabii fonlu (background) ve tabii fonsuz pikler.

$\mathrm{Bu}$ dalgalanmaları önleme spektrumların görsel şekli boyunca (mesela gürültünün oluşturduğu tabii fonda küçük pik bölgeleri bundan önemli ölçüde etkilenebilmektedir) önemli bir ihtiyaçtır. Ayrıca otomatik pik araştırma veya tabii fonu belirleme işlemlerinde de bu dalgalanmalar önleme önem arz etmektedir. Bu işleme spektrum düzleştirme de denir.

Spektrum düzleştirme yöntemlerinden biri Savitsky ve Golay (1964) tarafindan önerilen $\mathrm{n}$ boyutlu polinomik filtrelemelerdir. $\mathrm{Bu}$ yöntem deneysel verilerdeki istatistiksel dalgalanmaları veri noktaları boyunca en iyi fit denklemi ile yeniden oluşturmadır. Yani bu yöntem aynı $\mathrm{n}$ boyutlu bir polinomla deneysel tüm verilerin en yakın noktalarda yeniden tanımlanmasıdır. Yeteri kadar küçük $\Delta \mathrm{x}$ aralıkları sağlandığında;

$a_{0}+a_{1} x+a_{2} x^{2}+\ldots+a_{n} x^{r}$

ifadesi yazılabilir. Şayet $i_{0}$ merkezi kanalı etrafinda $y_{i_{0}-2}, y_{i_{0}-1}, y_{i_{0}}, y_{i_{0}+1}$ ve $y_{i_{0}+2}$ gibi veri noktalarının bir grubunu dikkate alırsak

$y(i)=a_{0}+a_{1}\left(i-i_{0}\right)+a_{2}\left(i-i_{0}\right)^{2}$ fonksiyonu ile en küçük kareler yöntemi ile fit işlemini gerçekleştirebiliriz. $a_{i}$ katsayılarını belirlediğimizde $\mathrm{i}_{0}$ merkezi kanalında polinomun değeri düzleştirilmiş değer olarak kullanılabilir (Van Espen ve Janssens, 1993):

$y_{i}^{*}=y\left(i_{0}\right)=a_{0}$

Merkezi kanalın sağa doğru kaydırılmasıyla ( $i_{0}$ dan $i_{0+1}$ e gidilmesi) bir sonraki kanaldaki içerik hesaplanabilir. $\mathrm{Bu} \quad \mathrm{a}_{\mathrm{i}}$ katsayılarının belirlenmesi

$a_{i}=\frac{1}{N_{i}} \sum_{j=-m}^{j=m} C_{i, j} y_{i+j}$

ifadesi ile mümkündür. $\mathrm{Bu}$ ifadeden ikinci derece polinomlar için

$$
\frac{C_{0, j}}{N_{0}}=\frac{3\left(3 m^{2}+3 m-1-5 j^{2}\right)}{(2 m-1)(2 m+1)(2 m+3)}
$$

katsayıları elde edilir. Herhangi bir pik bölgesi biri pik merkezi kanalı olmak üzere ve Gaussyen dağılım dikkate alındığında pik merkezinin sağında ve solunda asgari ikişer nokta olmalıdır. 
$\mathrm{Bu}$ nedenle bu çalışmada toplam beş noktayı içeren ikinci derece polinomal spektrum düzgünleştirme tercih edilmiştir:

$$
y_{i}^{*}=a_{0}=\frac{1}{35}\left(-3 y_{i-2}+12 y_{i-1}+17 y_{i}+12 y_{i+1}-3 y_{i+2}\right)
$$

\subsubsection{RAPOR Programı}

SMOOTH programin sonucu olarak yazdirılan uygun uzantılı spektrum dosyas1 adı ve spektrumdaki kanal sayısı girilerek pik bölgesi ile ilgili bilgilerin alınacağ 1 spektrum dosyası açılır. Her bir kanaldaki sayma bir değişkene atanır. Her bir kanaldaki net sayma değeri netsayma(i) değerine atanır. Burada i kanal numarasını göstermektedir. Net saymanın sıfırdan farklı olduğu kısımlar için aşağıdaki irdelemeler yapılarak pik bölgesi belirlenir. Pik bölgesinin başladığı kanal için

$$
\text { pikkanbas }=i\left\{\begin{array}{l}
\operatorname{netsayma}(i)=0 \\
\operatorname{netsayma}(i+1) \geq 0
\end{array}\right.
$$

ifadesi dikkate alınırken pik bölgesinin bittiği kanal için

$$
\text { pikkanbit }=i\left\{\begin{array}{l}
\operatorname{netsayma}(i+1)=0 \\
\operatorname{netsayma}(i) \geq 0
\end{array}\right.
$$

şartı dikkate alınır. Böylece pik bölgesinin genişliği

$$
\text { pikgen }=\text { pikkanbit }- \text { pikgenbas }
$$

ile elde edilir. Pik bölgesinin belirlenmesinde dikkate alınan diğer bir ölçüt pik genişliğinin yukarıda da ifade edildiği üzere en az beş olmasıdır. Buna bağlı olarak pik bölgesindeki pik merkezinin spektral karşılığı pik genişliğinin yarısı alınarak ya pik başlama kanalına ilave edilerek ya da pik bitiş kanalından çıkarılarak elde edilir. Pik bölgesindeki net sayma yukarıdaki ölçütleri sağlayan pik bölgesi içinde kalan tüm kanallardaki tabii fondan arındırılmış net saymaların toplanması ile elde edilir. $\mathrm{Bu}$ şekilde elde edilen spektrum bilgileri kullanıcı tarafindan adlandırılan bir rapor dosyası halinde yazdırılır.

\subsubsection{GRAPH Programı}

Graph programı bu proje kapsamında özgün olarak tasarlanmıştır. $\mathrm{Bu}$ program istenilen spektrum dosyasının açılmasıyla veriler uygun bir ölçeklendirme ile grafik üzerine aktarılmaktadır. Grafik ekranı dikey ve yatay 1zgaralara sahiptir. Bu, spektrum ile ilgili birtakım bilgilerin doğrudan analizci tarafından elde edilmesi imkânı sağlar. Ayrıca grafik ekranı istenilen boyutlarda ayarlanma özelliğine sahiptir. Böylece kullanıcı istenilen bölgedeki pik ile ilgili daha doğru bilgiler alabilme özgürlügüne sahip olabilmektedir.

$\mathrm{Bu}$ grafik penceresinde farenin sol tuşu kullanılarak istenilen alanlarda büyütme veya küçültme yapılabilmektedir. Böylece kullanıcı istenilen bölgedeki pik ile ilgili daha doğru bilgiler alabilme özgürlügüne sahip olabilmektedir.

\subsection{5. ÖZDU (Ölü Zaman Düzeltme Uygulaması) Arayüz Programı}

Bu proje kapsamında geliştirilen ÖZDU “Ölü Zaman Düzeltme Uygulaması" yazılımı Embarcadero Firmasının yazılımı geliştirme ortamı olan Delphi XE8 (Embarcadero, 2015) üzerinde geliştirilmiştir. Delphi programlama dilinin temeli Pascal dilidir. Özellikle nesne yönelimli programlama anlayışıyla yapılandırılmış Turbo Pascal dilinin görsel sürümü denilebilir. Nesne, sınıf, kalıtım, fonksiyon aşırıyükleme (overloading) gibi temel NYP tekniklerini ve daha fazlasını içeren ve $\mathrm{C}++$ den aşağı kalmayan güçlü ve esnek bir programlama dilidir (Wikipedia, 2015). Yazılımın kavramsal çerçevesi ve kullanılan yöntemlerin algoritmik yapısı açık kaynak kodlu Free Pascal 2.6.4 derleyicisi (Freepascal, 2015) üzerinde oluşturulmaya başlanmış ve son hali görsel arayüz avantajından dolayı Delphi XE8 derleyicisinin 30 günlük deneme sürümünde oluşturulmuştur. Yazılımın geliştirilmesi için kullanılan bilgisayar; Intel i5-2500 işlemci, 8 GB RAM Bellek ve grafik performansinı artıran Geforce GTX 770 işlemci 4 GB'lık belleği olan bir ekran kartına sahiptir. Bilgisayar üzerinde 64 bitlik Windows 8 işletim sistemi bulunmaktadır. 
ÖZDU programında kullanılacak olan parametreler ve komutlar tek bir arayüz üzerinden girilecek şekilde hazırlanmıştır. Her bir aşamanın sonucu farklı "Kaydet" butonları ile ayrı ayrı dosyalara yazdırılabilir. Yazılımın ilk giriş arayüzü aşağıdaki gibidir.

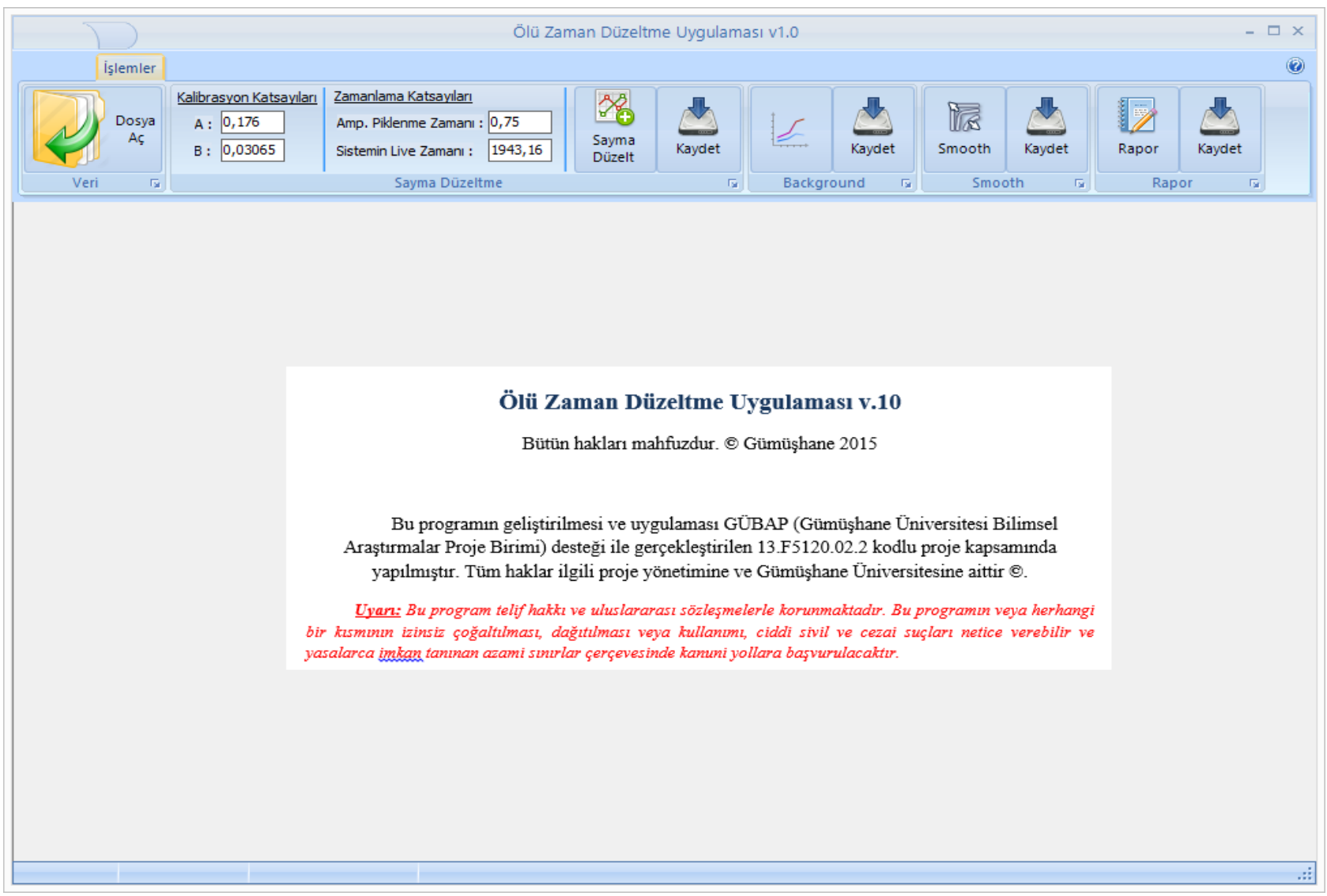

Şekil 6. ÖZDU program arayüzünün genel bir görünümü.

\section{Bulgular, Sonuç ve Tartışma}

ÖZDU arayüzü üzerinde açılması istenen spektrum dosyası ile ilgili dışarıdan girilmesi gerekli olan bilgilerin bulunduğu bir bölüm mevcuttur. $\mathrm{Bu}$ bölüm kanallara karşılık gelecek enerji değerlerini belirlemek için gerekli olan enerji kalibrasyon katsayılarını, yükselticinin piklenme zamanını ve açılması istenen spektrumun işlem (live) zamanını içerir. $\mathrm{Bu}$ bilgilerin girilmesi gereklidir. Arayüz üzerinde bulunan dosya aç butonu ile programın kurulu olduğu bilgisayarda istenilen yerdeki spektrum dosyası açılabilir.

$\mathrm{Bu}$ pencere üzerinden açılması istenen spektrum dosyası açılır. Dosya açıldığında o dosya ve içindeki verilerle ilgili genel bilgilerin olduğu Dosya Özellikleri penceresi belirir. Burada spektrum dosyası ile ilgili bir takım bilgiler mevcuttur. Bu bilgiler arasında bulunan ve programın diğer aşamalarında kullanılması gereken kanal sayısı doğrudan dosyadaki eleman sayısı kullanılarak alınabilmektedir.

Açılan spektrumla ilgili ölü zaman düzeltmesi yapabilmek için bu program çağrılmalıdır. Bunun için ÖZDU arayüz programında gerekli parametreler girildiğinde düzetme işlemi için "Sayma Düzelt" düğmesine ve sonucu kaydetmek için "Kaydet" düğmesine tıklanmalıdır. "Sayma Düzelt" düğmesine basıldığında hem spektrumla ilgili düzeltme yapılır hem de hesaplanan Toplam Ölü Zaman ve Toplam Analog Dijital Çevirici (ADC) Çevirme Zamanı sonuç ekranında gösterilmektedir. Düzeltme işleminden sonra hem orijinal veri hem de düzeltilmiş veri aynı grafik üzerinde farklı renklerle gösterilmekte 
ve böylece kullanıcı aradaki fark1 görebilmektedir.

Ölü zaman düzeltmesi yapılan spektrum dosyası "Kaydet" düğmesi ile istenilen bir metin (text) dosyası olarak kaydedilebilir. Sayma Düzeltme aşamasındaki işlemlerin benzerleri ÖZDU arayüzü üzerinde bulunan programda özgün pik arama modülü olan BACKGROUND, spektrum düzleştirme işlemini yapan SMOOTH ve spektrum ilgili bilgilerin verileceği RAPOR aşamaları içinde gerçekleştirilebilir.

Gama 1şınları için alınmış ölü zaman düzeltmesi yapılmayan bir spektrum örneği için sırasıyla BACKGROUND, SMOOTH ve RAPOR programları çağrılarak aşağıda Tablo 1 'de verilen spektrum bilgileri ÖZDU programiyla elde edildi. Bu rapor sonucuyla elde edilen bilgilerle katkılandırılmış beton bloğunun ölü zaman düzeltmesi yapılmamış lineer soğurma katsayısı hesaplanmıştır.

Tablo 1. Ölü zaman düzeltmesi yapılmamış spektrumun sonuç raporu.

$\begin{array}{lrrrrr}\text { PIK NO } & \text { PIK BAS. } & \text { PIK } \text { BIT. } & \text { PIK MER. } & \text { NET SAY. } & \text { HATA } \\ ----- & ------ & ------- & ------ & ------- & ----- \\ 1 & 11 & 25 & 18.0 & 149864 & 387.12 \\ 2 & 29 & 42 & 35.5 & 152338 & 390.31 \\ 3 & 58 & 70 & 64.0 & 5280 & 72.66 \\ 4 & 77 & 87 & 82.0 & 96 & 9.80 \\ 5 & 90 & 95 & 92.5 & 237 & 15.39 \\ 6 & 97 & 106 & 101.5 & 250 & 15.81 \\ 7 & 109 & 123 & 116.0 & 36 & 6.00 \\ 8 & 127 & 135 & 131.0 & 138 & 11.75 \\ 9 & 164 & 174 & 169.0 & 711 & 26.66 \\ 10 & 179 & 184 & 181.5 & 590 & 24.29 \\ 11 & 186 & 191 & 188.5 & 743 & 27.26 \\ 12 & 206 & 214 & 210.0 & 401 & 20.02 \\ 13 & 217 & 289 & 253.0 & 2446278 & 1564.06 \\ 14 & 324 & 337 & 330.5 & 10 & 3.16 \\ 15 & 360 & 394 & 377.0 & 36 & 6.00 \\ 16 & 397 & 431 & 414.0 & 5 & 2.24 \\ 17 & 445 & 480 & 462.5 & 5 & 2.24 \\ 18 & 508 & 514 & 511.0 & 7 & 2.65 \\ 19 & 524 & 534 & 529.0 & 5 & 2.24 \\ 20 & 686 & 763 & 724.5 & 5 & 2.24 \\ 21 & 858 & 874 & 866.0 & 11 & 3.32 \\ 22 & 1008 & 1014 & 1011.0 & 6 & 2.45\end{array}$

Aynı spektrumun ölü zaman düzeltmesi yapılan spektrumu için sırasıyla DÜZSAY, BACKGROUND, SMOOTH ve RAPOR programları çağrılarak aşağıda Tablo 2'de verilen spektrum bilgileri ÖZDU programıla elde edildi. Benzer şekilde bu rapor sonucuyla elde edilen bilgilerle katkılandırılmış beton bloğunun ölü zaman düzeltmesi yapılmıştır. Buna ek olarak bazı inşaat malzemeleri içerisinde doğal radyoaktivite belirleme için alınan gama ışını spektrumuna da bu program uygulanmıştır. Ayrıca x 1şınları içinde bu program uygulanarak test edilmiştir.
Gama 1şını çalışmalarında spektrometrenin pikleşme zamanı 1.5 mikrosaniyedir. Gama ışınları dikkate alınarak sistemin ölü zaman kaybı katkılandırılmış bazı beton blokların soğurma katsayısı belirlenmiștir. \%25 Barit ve \%75 Kireç Taşı'ndan oluşan beton bloğun soğurma katsayısı aşağıda Tablo 8'de verilmiştir. Buradan görüldüğü üzere ölü zaman düzeltmesi yapılan katkılı bu beton bloğun soğurma katsayısı ölü zaman düzeltmesi yapılmayana göre yüksek çıkmıştır. Bu katkılı betonun teorik soğurma katsayısı literatürde mevcut olmadığından teorik karşılaştırılması yapılamamıştır. 
Tablo 2. Ölü zaman düzeltmesi yapılmış spektrumun sonuç raporu.

$\begin{array}{lrrrrrr}\text { PIK NO } & \text { PIK BAS. } & \text { PIK } \text { BIT. } & \text { PIK MER. } & \text { NET SAY. } & \text { HATA } \\ ----- & ------- & ------- & ------ & ------ & ----- \\ 1 & 10 & 187 & 98.5 & 3769264 & 1941.46 \\ 2 & 202 & 288 & 245.0 & 2993666 & 1730.22 \\ 3 & 304 & 310 & 307.0 & 48 & 6.93 \\ 4 & 314 & 322 & 318.0 & 148 & 12.17 \\ 5 & 330 & 337 & 333.5 & 72 & 8.49 \\ 6 & 369 & 377 & 373.0 & 73 & 8.54 \\ 7 & 418 & 425 & 421.5 & 77 & 8.77 \\ 8 & 566 & 578 & 572.0 & 249 & 15.78 \\ 9 & 583 & 591 & 587.0 & 25 & 5.00 \\ 10 & 669 & 675 & 672.0 & 45 & 6.71 \\ 11 & 679 & 704 & 691.5 & 6 & 2.45 \\ 12 & 951 & 967 & 959.0 & 17 & 4.12 \\ 13 & 981 & 1006 & 993.5 & 236 & 15.36\end{array}$

Tablo 3. Beton bloğun lineer soğurma katsayısı.

\begin{tabular}{|c|c|c|c|}
\hline \multirow{2}{*}{ Beton Sınıfi } & \multirow{2}{*}{ Beton Türü } & \multicolumn{2}{|c|}{ Deneysel Lineer Soğurma Katsayı1s1, $\mu(1 / \mathrm{cm})$} \\
\cline { 3 - 4 } & & Ölü Zaman Düzeltilmemiş & Ölü Zaman Düzeltilmiş \\
\hline \multirow{2}{*}{ C16 } & 25B75KT & 0.196 & 0.205 \\
& & & \\
\hline
\end{tabular}

*Ertaş (2014)

$\mathrm{Bu}$ çalıșma kapsamında şu ana kadar literatürde var olan ölü zaman düzeltme yöntemlerinden farklı bir yöntem önerilmiştir. $\mathrm{Bu}$ özgün ölü zaman düzeltme yönteminde tamamen spektrometrenin elektronik yapısı üzerine odaklanmış ve buna bağlı olarak elektronik aygıtlardan kaynaklanan ölü zaman ifadesi türetilmiştir. Yine çalışma kapsamında özgün bir pik arama yöntemi ifade edilmiş olup bu yöntemin istenilen düzeyde pik bulması yapılan çalışmalar sonucu görülmüştür. Buna ek olarak yine özgün bir grafik modülü tasarımı gerçekleştirilerek kullanıcıya etkin bir pik araştırma imkânı sunulmuştur. Aynı zamanda kullanıcı bu grafik üzerinde ölü zaman düzeltmesi yapılmış ya da yapılmamış pikleri karşılaştırma imkânına sahip olmuştur.

Çalışma kapsamında geliştirilen yazılım alınan spektrum ölçümleri ile birçok kez test edilmiş ve sonuçların beklendiği ölçüde gerçekleştiği görülmüştür. $\mathrm{Bu}$ nedenle bu testler ile ilgili bazı örneklere yukarıda yer verilmiştir.

Çalışma süresince, başlangıçta öngörülmeyen yüksek hızlı bozunma oranlarına sahip radyoaktif çekirdekler için ölü zaman düzeltmesi, pile up pikleri etkisi gibi bir takım spektrometrik sonuçlar belirlenmiştir. Aynı zamanda bazı üst üste binmiş piklerin ayrilamamas1, bunun sonucunda pik genişliklerinin büyük olması ve buna bağlı olarak pik merkezinde bazı kaymalara rastlanmıştır. $\mathrm{Bu}$ sıkıntılar spektrum sonuçlarının doğruluğunu etkilememekle birlikte yapılan çalışmalarla bunlar giderilecektir.

Sonuç olarak, bu çalışmada önerilen integral düzeltme yöntemiyle uzatılan ve uzatılmayan sistem ölü zamanları olarak ifade edilen iki mekanizmanın birleşiminden ileri gelen sayma kayıplarını istenilen doğrulukta telafi edilebilir. Sayma sisteminin ölü zamanı 
analitik bir formül ile belirlenebilir. $\mathrm{Bu}$ ölü zaman boyunca oluşan sayma kayıpları Poisson davranışına uyan düzeltilmemiş spektrum göz önünde bulundurularak telafi edilebilir. Bu yeni yöntem sabit düşük sayma oranlarında sayma kaybını yeteri kadar düzeltebilmektedir (Karabıdak, 2013).

Ayrica bu projede önerilen ÖZDU arayüz programı kullanıcı dostu modern bir arayüze sahiptir. İleride yapılacak olan güncellemeler bu arayüz tasarımında dikkate alınmıştır. $\mathrm{Bu}$ arayüzün tasarımda bu program ile ilgili yapılacak diğer versiyonlar yani program geliştirme çalışmaları devam edecektir.

\section{Teşekkür}

Bu çalışma, Gümüşhane Üniversitesi Bilimsel Araştırma Projeleri (GÜBAP) birimi tarafindan 13.F5120.02.2 nolu proje kapsamında desteklenmiştir.

\section{Kaynaklar}

Blaauw, M., Fleming, R. F. ve Keyser R., 2001. Digital signal processing and zero dead time counting, Journal of Radioanalytical and Nuclear Chemistry, 248, 309-313.

Blaauw, M. ve Fleming, R. F., 2003. Statistical Properties of Gamma-Ray Spectra Obtained with Loss-Free or Zero-Dead-Time Counting, and ORTEC'S "Variance Spectrum". Nuclear Instruments and Methods, A 505; 306-310.

Damla, N., 2009, Türkiye'deki Bazı İnşaat Malzemelerinde Doğal Radyaoktiflik Seviyelerinin Ve Kütle Soğurma Katsayılarının Belirlenmesi. Doktora Tezi, Karadeniz Teknik Üniversitesi Fen Bilimleri Enstitüsü. Trabzon, 125s.

Embarcadero,http://www.embarcadero.com/p roducts/delphi. 20 Mayıs 2015.

Ertaş, H., 2014, Kurşun Madeni Atıklarının Radyasyon Zirhlama Etkilerinin
Araştırılması. Yüksek Lisans Tezi, Gümüşhane Üniversitesi Fen Bilimleri Enstitüsü. Gümüşhane, 92s.

Freepascal, http://www.freepascal.org/. 25 Mayıs 2015.

Genie 2000, 2000, Customize Manual.

Gilmore, G. ve Hemingway, J.D., 2003, Practical Gamma-Ray Spectrometry, Willey, New York, $314 p$.

Jenkins, R., Gould, R. W. ve Gedcke, D., 1981, Quantitative X-Ray Spectrometry, Marcel Dekker, New York, 475p.

Karabıdak, S. M., 2013. X ve Gama-Işını Dedektörlerinde Ölü Zaman Düzeltmesi - Kısım 1-İntegral Düzeltme, Gümüșhane Üniversitesi Fen Bilimleri Enstitüsü Dergisi, 3(2), 91-100.

Knoll, G. F., 2000, Radiation Detection and Measurement, Third Edit., Wiley, New York, 802p.

Savitzky, A. ve Golay, M. J. E., 1964, Smoothing and Differentiation of Data by Simplified Least Squares Procedures, Analytical Chemistry, 38 (8); 1627-1639.

Van Espen, P. J. M. ve Janssens, K. H. A., 1993, Handbook of X-Ray Specktrometry-Methods and Techniques. Van Grieken, R. E. and Markowicz, A. A (eds.), Marcel Dekker Inc., New York. pp.181-293.

Wikipedia,https://tr.wikipedia.org/wiki/Delph i_(programlama_dili). 20 Mayıs 2015. 